\title{
A Covariance Structure Analysis for Fraudulent Reporting: Evidence from Japan
}

\author{
Masumi Nakashima. Ph.D. \\ Professor of Accountancy \\ Bunkyo Gakuin University \\ mnakashima@bgu.ac.jp
}

\begin{abstract}
This study explores whether six categories of earnings management determinants such as useful-decisions, financial performance, accounting standards, governance and internal controls, auditors, and law enforcement influence earnings management for misrepresentation simultaneously to validate the relationships. This study contributes to the literature in the following ways. First, this study employs a structural equation modeling (SEM) by using the responses from the survey of 115 questionnaires for CFOs of the public firms in Japan. Second, I present a new framework that incorporates the theoretical concepts by applying the Theory of Planned Behavior, Protection Motivation Theory, and the Deterrence Theory to explain how variables influence earnings management for misrepresentation. The results of the analysis show that while accounting standards have a significant negative effect on earnings management for misrepresentation, governance and internal controls have a positive effect on earnings management to misrepresent earnings.
\end{abstract}

Keywords: Structural equation modeling; attitudes/rationalization, misrepresentation, earnings management; planned behavior theory; protection motivation theory. 